\title{
Studi Etnobotani Tumbuhan Upacara Ritual Adat Kelahiran di Desa Banmati, Kecamatan Tawangsari, Kabupaten Sukoharjo
}

\author{
As Syaffa Al Liina, Husna Ainun Fauziah, dan Nurmiyati \\ Pendidikan Biologi, Fakultas Keguruan dan Ilmu Pendidikan, Universitas Sebelas \\ Maret \\ Jl. Ir. Sutami No.36A, Jebres, Kota Surakarta, Jawa Tengah 57126 \\ e-mail: husnaainunfauziah@student.uns.ac.id
}

\begin{abstract}
Abstrak
Upacara ritual adat kelahiran merupan tindakan yang dilakukan sebelum maupun sesudah proses kelahiran yang dilakukan oleh masyarakat berdasarkan adat yang belaku di suatu daerah tertentu. Upacara ritual adat kelahiran dilakukan secara turun temurun oleh masyarakat setempat. Setiap kegiatan upacara adat yang dilakukan demi kesejahteraan keberlangsungan hidup bayi. Beragam tumbuhan digunakan dalam upacara adat kelahairan. Masyarakat Desa Banmati merupakan masyarakat yang masih menggunakan tumbuhan-tumbuhan sebagai bahan prosesi upacara ritual adat kelahiran. Penelitian ini bertujuan untuk mengetahui tumbuh-tumbuhan yang dimanfaatkan sebagai bahan upacara adat kelahiran, cara penggunaan tumbuhan dalam upacara adat kelahiran, dan cara memperoleh tumbuhan yang digunakan dalam adat kelahiran oleh masyarakat Banmati. Pengambilan sampel penelitian dilakukan dengan teknik Purposive Sampling. Pengumpulan data didapatkan melalui wawancara Semi-Stuctured. Hasil penelitian menunjukkan bahwa terdapat 14 spesies tumbuhan yang digunakan pada prosesi upacara adat oleh masyarakat Banmati kabupaten Sukoharjo.
\end{abstract}

Kata Kunci-Adat kelahiran, Etnobotani, Sukohajo, Tumbuhan

\begin{abstract}
Ritual birth ceremony is an action that clone either before or after birth process. This ritual based on a custom which is used in a certain area. Ritual birth ceremony is done hereditary for generations in a certain area. The purpose of the ritual is to guarantee the baby welfare. Several plants is used in ritual birth ceremony. Some people in Banmati village is still used several plants in ritual birth ceremony. This research aims to recognize plants which are used as ingredients in ritual birth ceremony, the way of using plants in ritual birth ceremony, and the process in searching plants that used in ritual birth ceremony in Banmati. The collecting of data use purposive sampling technique. The collecting data is done through semi structured interview. The result of the research show that there are 14 spesies of plants which used in ritual birth ceremony in Banmati society in Sukoharjo regency.
\end{abstract}

Keywords: Birth ceremony, Etnobotany, Sukoharjo, Plants

\section{PENDAHULUAN}

Masyarakat Indonesia dalam kehidupan sehari-hari memiliki budaya yang masih dominan akan unsur-unsur tradisional. Keadaan ini didukung oleh keanekaragaman hayati yang berasal dari berbagai ekosistem yang ada di Indonesia. Selain pemanfaatan keanekaragam hayati telah melalui sejarah panjang sebagai bagian dari kebudayaan (Rahyuni, Yniati, \& Pitopang, 2013).

Indonesia sebagai negara yang kaya akan suku budaya masyarakat juga kaya akan keanekaragaman jenis tumbuhan. Tumbuhan merupakan keanekragaman hayati yang selalu ada di sekitar kita, baik yang tumbuh liar ataupun yang sudah dibudidayakan. (Yuniati \& Alwi, 2010). Masyarakat tradisional telah lama memanfaatkan keanekaragaman hayati atau sumber daya alam yang ada di sekelilingnya (Sukmawati \& Yuniati, 2013). Karena kehidupan masyarakat tradisional yang sangat dekat dengan sumberdaya alam dan lingkungan, sehingga salah satu interaksi yang muncul berhubungan dengan pemanfaatan tum- 
buhan (Atok, Hikmat, \& Zuhud, 2010).

Etnobotani adalah cabang keilmuan yang mempelajari hubungan langsung antara manusia dengan tumbuhan dalam hal pemanfaatan dan pengelolaannya terutama pada masyarakat tradisional (Atok et al., 2010). Etnobotani memiliki potensi untuk mengungkapkan sistem pengetahuan tradisional suatu kelompok masyarakat atau etnis mengenai keanekaragaman sumberdaya hayati, konservasi dan budaya (Tapundu \& Anam, 2015).

Kabupaten Sukoharjo merupakan daerah yang mayoritas masyarakatnya adalah suku Jawa. Masyarakat suku Jawa mengembangkan budayanya salah satunya dalam penggunaan keanekaragaman tanaman. Hal ini sesuai dengan salah satu dari empat ciri budaya yakni budaya merupakan sikap dan perilaku yang dilaksanakan secara turun temurun tanpa memikirkan rasionalitas budya tersebut dan dilakukan sesuai den kondisi kebutuhan kelompok masyarkat yang melaksanakan budaya. Kelompok masyarakat Jawa di kabupaten Sukoharjo memiliki budaya dan tradisi dengan persepsi tertentu dalam penggunaan tanaman (Boyle dan Andrews, 1989)

Tumbuhan digunakan dalam berbagai ritual adat salah satunya ritual adat kelahiran (Rahyuni et al., 2013). Masyarakat suku jawa umumnya memiliki upacara adat kelahiran yang terbagi menjadi beberapa tahapan diantaranya: tingkeban/mitoni pada bulan ketujuh kandungan, dan setelah kelahiran: perawatan ari-ari (plasenta), tinggalnya sisa tali pusar, sepasaran, selapanan, dan selanjutnya selamatan weton pada setiap hari kelahiran (siklus 35 hari) (Risdianawati \& Hanif, 2015).

Upacara ritual adat kelahiran terutama di wilayah Sukoharjo belum diketahui jenis-jenis tumbuhan yang digunakan untuk upacara adat secara etnobotani, sehingga perlu dilakukan studi etnobotani khususnya mengenai macam-macam tumbuhan yang digunakan dalam upacara ritual adat kelahiran.

\section{METODE PENELITIAN}

Penelitian ini dilaksankan di Desa Banmati, Kecamatan Tawangsari, Kabupaten Sukoharjo. Penelitian dilakukan pada bulan Desember 2017. Jenis penelitian ini adalah deskriptif eksploratif.
Adapun metode yang digunakan adalah dengan metode wawancara semi-terstruktur (semi-structured interview).

Pengumpulan data dilakukan dengan wawancara terhadap sejumlah responden. Penentuan responden yang ditentukan secara terpilih (metode purposive sampling). Responden yang dipilih antara lain dukun bayi, tetua desa, dan masyarakat masing-masing daerah yang mengetahui tentang etnobotani kelahiran. Alat yang digunakan adalah alat tulis, perekam suara, dan lembar wawancara.

Bahasa yang digunakan dalam wawancara adalah bahasa Jawa dan bahasa Indonesia disesuaikan dengan kemampuan responden. Analisis data dalam penelitian ini menggunakan teknis analisis deskriptif kualitatif. Analisis ini merupakan analisis isi (content analysis) berdasarkan data pengetahuan responden terhadap tumbuhan untuk upacara kelahiran. Data kualitatif didapat dari hasil wawancara masyarakat untuk mengatahui jnis tumbuhan, tujuan menggunakan jenis tumbuhan tertentu, sumber perolehan dan cara pemanfaatan tumbuhan yang digunakan sebagai bahan upacara adat kelahiran.

\section{HASIL DAN PMBAHASAN}

Berdasarkan hasil penelitian dan wawancara dari beberapa responden yaitu masyarakat yang mengetahui mengenai adat kelahiran (dukun bayi), tokoh masyarakat, dan masyarakat umum yang masih melaksanakan ritual adat kelahiran. Diketahui bahwa terdapat beberapa upacara ritual adat yang dilaksanakan sebelum dan sesudah kelahiran diantaranya ngebor-ebori, mitoni, mencuci ari-ari, sepasaran, puputan, mendhem ari-ari atau ngelarung ari-ari, dan selapanan.

\section{A. Upacara Ritual Adat Sebelum Kelahir- an dan Tumbuhan yang Digunakan}

\section{1) Ngebor-ebori (4 bulan kehamilan)}

Upacara adat yang biasa dilakukan adalah menyajikan bubur sum-sum yang terbuat dari tepung beras (Oryza sativa) yang nantinnya akan dimakan oleh ibu hamil dan akan disajikan untuk tetangga sekitar rumah. Tujuannya ibu hamil memakan bubur sum-sum agar ibu dan bayi selalu selamat sebelum kelahiran. 


\section{2) Mitoni (7 bulan kehamilan)}

Adat yang biasa dilakukan adalah siraman dengan menggunakan air yang diberi tambahan bunga setaman yang terdiri atas mawar (Rosa sp.), melati (Jasminum sambac), dan kenanga (Cananga odorata), dan kunir (Curcuma longa). Prosesinya air yang sudah diberi tambahan bunga setaman dan kunyit disiramkan kepada ibu hamil dan suaminya. Saat prosesi siraman ibu hamil menggunakan kain jarik 7 lapis yang digunakan bertahap selama prosesi siraman. Tujuan menggunakan bunga setaman saat siraman adalah untuk memberikan kesegaran dan kesehatan kepada ibu hamil dan bayi yang ada dalam kandungan.

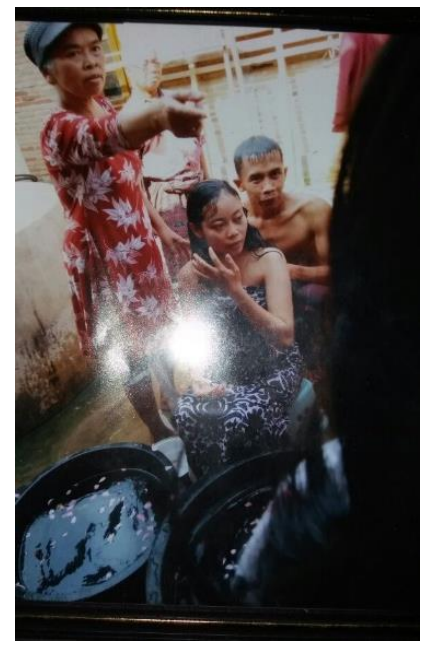

Gambar. 1. Prosesi adat siraman saat upacara adat kelahiran mitoni (7 bulan kehamilan). Sumber : Foto Narasumber

Setelah siraman dilakukan ritul lainnya dengan menggunakan kelapa cengkir atau kelapa yang muda (Cocos nucifera). Kelapa pertama dibuat rujakan dan yang kelapa yang kedua dipecah. Kelapa yang dipecah digambar tokoh pewayangan janaka dan srikandi. Tujuan memecah kelapa adalah agar ibu hamil dalam prosesi kelahirannya diberi kelancaran dan menggambar tokoh pewayangan pada kelapa bertujuan agar anak yang yang lahir nantinya rupanya tampan seperti janaka atau cantik seperti srikandi.
Tabel 1.

Upacara Ritual Adat Sebelum Kelahiran

Nama Tumbuhan dan Organ Tumbuhan yang digunakan

\begin{tabular}{|c|c|c|}
\hline $\begin{array}{l}\text { Nama Upacara Adat } \\
\text { Sebelum Kelahiran }\end{array}$ & $\begin{array}{c}\text { Nama Tumbuhan yang } \\
\text { digunakan }\end{array}$ & $\begin{array}{c}\text { Organ } \\
\text { Tumbuhan } \\
\text { yang } \\
\text { digunakan }\end{array}$ \\
\hline $\begin{array}{c}\text { Ngebor-ebori } \\
\text { (4 bulan kehamilan) }\end{array}$ & Padi (Oryza sativa) & Biji \\
\hline \multirow{5}{*}{$\begin{array}{c}\text { Mitoni } \\
\text { (7 bulan kehamilan) }\end{array}$} & Mawar (Rosa sp.) & Bunga \\
\hline & $\begin{array}{l}\text { Melati (Jasminum } \\
\text { sambac) }\end{array}$ & Bunga \\
\hline & $\begin{array}{c}\text { Kenanga (Cananga } \\
\text { odorata) }\end{array}$ & Bunga \\
\hline & $\begin{array}{l}\text { Kunir (Kunyit) } \\
\text { (Curcuma longa) }\end{array}$ & Umbi \\
\hline & Kelapa (Cocos nucifera) & Buah \\
\hline Mencuci ari-ari & $\begin{array}{c}\text { Waru (Hibiscus } \\
\text { tiliaceus) }\end{array}$ & Daun \\
\hline
\end{tabular}

\section{B. Upacara Ritual Adat Sesudah Kelahir- an dan Tumbuhan yang Digunakan}

\section{1) Mencuci ari-ari}

Setelah kelahiran apabila hendak mencuci ari-ari digunakan daun waru (Hibiscus tiliaceus) sebagai tempat meletakkan ari-ari yang akan dicuci. Tujuan penggunannya tidak dijabarkan secara khusus, karena sudah merupakan adat turun temurun yang biasa dilakukan.

\section{2) Sepasaran (5 hari setelah kelahiran)}

Sepasaran dilakukan 5 hari setelah kelahiran bayi. Keluarga yang memiliki bayi membuat masakan berupa nasi urap yang di dalamnya terdiri atas 7 macam sayuran yakni daun turi (Sesbania grandiflora), daun kenikir sayur (Cosmos caudatus), daun pace (Morinda citrifolia), daung kangkung (Ipomoea aquatica), daun singkong (Manihot esculenta), dan sayur pelengkap lainnya. Makanan yang telah dimasak nantinya kan dibagikan ke tetangga sekitar rumah. Tujuan memasak makanan adalah sebagai wujud rasa syukur atas kelahiran si bayi dan agar si bayi tetap sehat selalu.

\section{3) Puputan (Lepasnya ari-ari Bayi)}

Upacara yang dilakukan adalah membuat masakan berupa nasi kerucut yang diberi cabai (Capsicum annum) dan bawang merah (Allium cepa var. Aggregatum). Selain itu menyediakan gelas berisi air yang diberi bunga setaman yang terdiri atas mawar (Rosa sp.), melati (Jasminum 
sambac), dan kenanga (Cananga odorata) dan air kelapa (Cocos nucifera). Masakan nantinya akan dibagikan ke tetangga sekitar. Tujuan membuat masakan adalah sebagai wujud rasa syukur penggunaan cabai dan bawang merah dianggap sebagai penolak bala. Gelas berisi air yang diberi bunga setaman dan air kelapamerupakan bentuk sesaji.

\section{4) Mendhem ari (Mengubur ari-ari) atau Ngelarung ari (Menghanyutkan ari- ari)}

Bayi yang ari-arinya telah lepas selanjutnya ari-ari nya akan dikubur atau pilihan lainnya dapat dihanyutkan di sungai. Apabila dikubur, ari-ari akan dikubur dalam kendi dengan di dalamnya diberi tambahan beras (Oryza sativa), bunga setaman (mawar (Rosa sp.), melati (Jasminum sambac), dan kenanga (Cananga odorata). Penguburannya diletakkan di depan rumah untuk laki-laki di sebalah kanan dan perempuan disebelah kiri. Tujuan menambahkan beras dan bunga setaman adalah sebagai bekal untuk si ariari yang dianggap merupakan saudara dari si bayi.

Apabila ari-ari hendak dihanyutkan, maka dalam wadah untuk menghanyutkan ari-ari diberi beras (Oryza sativa) dan kunir (Curcuma longa). Ari-ari dihanyutkan di sungai Bengawan Solo. Tujuan menambahkan beras dan kunir adalah sebagai bekal untuk si ari-ari yang dianggap merupakan saudara dari si bayi.

\section{5) Selapanan (35 hari setelah kelahiran )}

Selapanan atau 35 hari setelah kelahiran bayi memiliki adat yang hampir sama dengan sepasaran. Keluarga yang memiliki bayi membuat masakan berupa nasi urap yang di dalamnya terdiri atas 7 macam sayuran yakni daun turi (Sesbania grandiflora), daun kenikir sayur (Cosmos caudatus), daun pace (Morinda citrifolia), daung kangkung (Ipomoea aquatica), daun singkong (Manihot esculenta), dan sayur pelengkap lainnya. Makanan yang telah dimasak nantinya akan dibagikan ke tetangga sekitar rumah. Tujuan memasak makanan adalah sebagai wujud rasa syukur atas kelahiran si bayi dan agar si bayi tetap sehat selalu.
Tabel 2

Upacara Ritual Adat Sesudah Kelahiran Nama Tumbuhan dan Organ Tumbuhan yang digunakan

\begin{tabular}{|c|c|c|}
\hline $\begin{array}{c}\text { Nama Upacara Adat } \\
\text { Kelahiran }\end{array}$ & $\begin{array}{c}\text { Nama Tumbuhan yang } \\
\text { digunakan }\end{array}$ & $\begin{array}{c}\text { Organ } \\
\text { Tumbuhan } \\
\text { yang } \\
\text { digunakan }\end{array}$ \\
\hline \multirow{6}{*}{$\begin{array}{c}\text { Sepasaran } \\
\text { (5 hari setelah } \\
\text { kelahiran) }\end{array}$} & Padi (Oryza sativa) & Biji \\
\hline & $\begin{array}{c}\text { Turi (Sesbania } \\
\text { grandiflora) }\end{array}$ & Daun \\
\hline & $\begin{array}{c}\text { Kenikir (Cosmos } \\
\text { caudatus) }\end{array}$ & Daun \\
\hline & $\begin{array}{c}\text { Pace (Morinda } \\
\text { citrifolia) }\end{array}$ & Daun \\
\hline & $\begin{array}{c}\text { Kangkung (Ipomoea } \\
\text { aquatica) }\end{array}$ & Daun \\
\hline & $\begin{array}{c}\text { Singkong (Manihot } \\
\text { esculenta) }\end{array}$ & Daun \\
\hline \multirow{7}{*}{$\begin{array}{c}\text { Puputan } \\
\text { (Lepasnya ari-ari } \\
\text { Bayi) }\end{array}$} & Padi (Oryza sativa) & Biji \\
\hline & $\begin{array}{c}\text { Cabai (Capsicum } \\
\text { annum) } \\
\end{array}$ & Buah \\
\hline & $\begin{array}{l}\text { Bawang merah (Allium } \\
\text { cepa var. Aggregatum) }\end{array}$ & Umbi \\
\hline & Mawar (Rosa sp.) & Bunga \\
\hline & $\begin{array}{c}\text { Melati (Jasminum } \\
\text { sambac) }\end{array}$ & Bunga \\
\hline & $\begin{array}{c}\text { Kenanga (Cananga } \\
\text { odorata) }\end{array}$ & Bunga \\
\hline & Kelapa (Cocos nucifera) & Buah \\
\hline \multirow{5}{*}{$\begin{array}{c}\text { Mendhem ari } \\
\text { (Mengubur ari-ari) } \\
\text { atau } \\
\text { Ngelarung ari } \\
\text { (Menghanyutkan } \\
\text { ari-ari) }\end{array}$} & Padi (Oryza sativa) & Biji \\
\hline & Mawar (Rosa sp.) & Bunga \\
\hline & $\begin{array}{c}\text { Melati (Jasminum } \\
\text { sambac) }\end{array}$ & Bunga \\
\hline & $\begin{array}{c}\text { Kenanga (Cananga } \\
\text { odorata) }\end{array}$ & Bunga \\
\hline & $\begin{array}{c}\text { Kunir (Kunyit) } \\
\text { (Curcuma longa) }\end{array}$ & Umbi \\
\hline \multirow{6}{*}{$\begin{array}{c}\text { Selapanan } \\
\text { (35 hari setelah } \\
\text { kelahiran ) }\end{array}$} & Padi (Oryza sativa) & Biji \\
\hline & $\begin{array}{c}\text { Turi (Sesbania } \\
\text { grandiflora) }\end{array}$ & Daun \\
\hline & $\begin{array}{c}\text { Kenikir (Cosmos } \\
\text { caudatus) }\end{array}$ & Daun \\
\hline & $\begin{array}{c}\text { Pace (Morinda } \\
\text { citrifolia) }\end{array}$ & Daun \\
\hline & $\begin{array}{c}\text { Kangkung (Ipomoea } \\
\text { aquatica) }\end{array}$ & Daun \\
\hline & $\begin{array}{c}\text { Singkong (Manihot } \\
\text { esculenta) }\end{array}$ & Daun \\
\hline
\end{tabular}

\section{Cara Memperoleh Tumbuhan yang digunakan pada Upacara Adat Kelahiran}

Upacara Adat Kelahiran di Sukoharjo untuk tumbuhan yang digunakan dalam adat kelahiran seperti bubur sum-sum untuk ngebor-ebori, bunga setaman yang digunakan siraman saat mitoni, sayuran yang digunakan untuk nasi urap, semuanya diperoleh dengan cara membeli di pasar. Hal ini di karenakan sudah jarang warga yang menanam tumbuh-tumbuhan dengan tujuan un- 
tuk dipergunakan dalam kegiatan ritual adat seperti ritual adat kelahiran.

\section{KESIMPULAN}

Berdasarkan penelitian ini dapat ditarik kesimpulan bahwa upacara adat kelahiran yang dilaksankana di Desa Banmati, Kecamatan Tawangsari, Kabupaten Sukoharjo antaralain Ngebor-ebori (4 bulan kehamilan), Mitoni (7 bulan kehamilan), Mencuci ari-ari, Sepasaran (5 hari setelah kelahiran), Puputan (Lepasnya ari-ari Bayi), Mendhem ari (Mengubur ari-ari) atau Ngelarung ari (Menghanyutkan ari-ari), dan Selapanan (35 hari setelah kelahiran).

Tumbuhan yang digunakan dalam seluruh upacara adat kelahiran di Desa Banmati, Kecamatan Tawangsari, Kabupaten Sukoharjo ada 14 spesies tumbuhan antaralain : padi (Oryza sativa), mawar (Rosa sp.), melati (Jasminum sambac), kenanga (Cananga odorata), kunir (Curcuma longa), kelapa (Cocos nucifera), waru (Hibiscus tiliaceus), turi (Sesbania grandiflora), kenikir (Cosmos caudatus), pace (Morinda citrifolia), kangkung (Ipomoea aquatica), singkong (Manihot esculenta), cabai (Capsicum annum), dan bawang merah (Allium cepa var. Aggregatum)

Spesies tumbuhan yang paling banyak digunakan dalam upacara adat kelahiran adalah padi (Oryza sativa) dan bunga setaman yang terdiri atas mawar (Rosa sp.), melati (Jasminum sambac), dan kenanga (Cananga odorata).

\section{DAFTAR PUSTAKA}

Andrew, M.M and Boyle. J.S. (1989), Transkultural Conceps in care (2nd ed) Philelphia: JB. Lippincott Company

Rahyuni, Yniati, E., \& Pitopang, R. (2013). Kajian Etnobotani Tumbuhan Ritual Suku TAJIO di desa Kasimbar Kabupaten Paringi Mountong. Online Jurnal of Natural Science, 2(2), 46-54.

Risdianawati, L. F., \& Hanif, M. (2015). Sikap Masyarakat Terhadap Pelaksanaan Upacara Kelahiran Adat Jawa Tahun 2009-2014 (Studi Di Desa Bringin Kecamatan Kauman Kabupaten Ponorogo). JURNAL AGASTYA, 5(1), 30-66.

Sukmawati, N., \& Yuniati, E. (2013). Studi Etnobotani Tumbuhan Obat Pada Masyarakat Suku Kaili Rai di Desa Toga Kecamatan Ampibabo Kabupaten Parigi Moutong Sulawesi Tengah. Biocelebes, 7(2), 9-14.

Tapundu, A. S., \& Anam, S. (2015). Studi Etnobotani Tumbuhan Obat Pada Suku Seko Di Desa Tanah Harapan , Kabupaten Sigi, Sulawesi Tengah. Biocelebes, 9(2), 66-86.

Yuniati, E., \& Alwi, M. (2010). Etnobotani keanekaragaman jenis tumbuhan obat tradisional dari hutan di desa Pakuli kecamatan Gumbasa kabupaten Donggala , Sulawesi Tengah. Biocelebes, 4(1), 6. 